Int. J. Electrochem. Sci., 15 (2020) $2458-2469$

International Journal of

ELECTROCHEMICAL

SCIENCE

Www.electrochemsci.org

\title{
Miniaturised Electrochemical Analyser for Glucose Determination Based on Chitosan/GOD/Electroreduced Graphene Oxide Sensor
}

\author{
Zemin Zhang ${ }^{1,2}$, Huihuang $\mathrm{Wu}^{1,2}$, Yueming Gao ${ }^{1,2, *}$, Linke Huang ${ }^{1,2}$, Haibo Pan ${ }^{2}$, Ming Du ${ }^{1,3}$ \\ ${ }^{1}$ College of Physics and Information Engineering, Fuzhou University, Fuzhou 350116, China \\ ${ }^{2}$ Key Lab of Medical Instrumentation \& Pharmaceutical Technology of Fujian Province, Fuzhou \\ 350116, China \\ ${ }^{3}$ Key Lab of Eco-Industrial Green Technology of Fujian Province, Wuyi University, Nanping 354300, \\ China. \\ *E-mail: fzugym@gmail.com
}

doi: $10.20964 / 2020.03 .28$

Received: 18 October 2019 / Accepted: 20 December 2019 / Published: 10 February 2020

This paper aimed to design a miniaturised electrochemical analyser (MEA) for glucose determination based on the integration of chitosan (CS), glucose oxidase (GOD) and electroreduced graphene oxide (e-RGO). The low-power programmable analog front-end LMP91000 and the microcontroller STM32F103C8T6 were combined into the hardware system of the MEA. The potentiostat function of the system was realised by applying the setting potential on the three-electrode sensor. By setting the trans-impedance gain, the current can be converted from a full range of $5 \mu \mathrm{A}$ to $750 \mu \mathrm{A}$. The voltage signal was converted into the current signal using an algorithm to process the experimental results. Reliability of the MEA was verified by electrochemical workstation, and the performance was tested using a $\left[\mathrm{Fe}\left(\mathrm{CN}_{6}\right)\right]^{3-}$ solution. The MEA showed a good linear relationship between the final steadystate current and the $\left[\mathrm{Fe}\left(\mathrm{CN}_{6}\right)\right]^{3-}$ concentration in the dynamic range of $0.2 \mathrm{mM}$ to $10 \mathrm{mM}\left(R^{2}=\right.$ 0.9841). GOD was fixed on a working electrode (WE) modified with e-RGO to prepare the glucose sensor. Finally, different glucose concentrations were measured using chronoamperometry with the MEA. The MEA sensitivity reached $169.32 \mathrm{~mA} / \mathrm{M} \cdot \mathrm{cm}^{-2}$, and the limit of detection amounted to $0.19 \mathrm{mM}$ according to $3 \delta /$ slope calculation.

Keywords: Electrochemical detection, Miniaturization, Chitosan (CS), Glucose oxidase (GOD), electroreduced graphene oxide (e-RGO), Glucose. 
(C) 2020 The Authors. Published by ESG (www.electrochemsci.org). This article is an open access article distributed under the terms and conditions of the Creative Commons Attribution license (http://creativecommons.org/licenses/by/4.0/). 